Research Article

\title{
Green Synthesis of Highly Luminescent Carbon Quantum Dots from Lemon Juice
}

\author{
Bui Thi Hoan,,$^{1,2}$ Phuong Dinh Tam $\mathbb{D}^{1,3}$ and Vuong-Hung Pham ${ }^{1}{ }^{1}$ \\ ${ }^{1}$ Advanced Institute for Science and Technology (AIST), Hanoi University of Science and Technology (HUST), No 01, \\ Dai Co Viet Road, Hanoi, Vietnam \\ ${ }^{2}$ Faculty of Energy Engineering, Thuyloi University, No 175 Tay Son Road, Hanoi, Vietnam \\ ${ }^{3}$ Faculty of Material Science and Engineering, Phenikaa University, Yen Nghia, Ha-Dong District, Hanoi 1000, Vietnam
}

Correspondence should be addressed to Phuong Dinh Tam; tam.phuongdinh@phenikaa-uni.edu.vn and Vuong-Hung Pham; vuong.phamhung@hust.edu.vn

Received 18 December 2018; Revised 10 March 2019; Accepted 21 March 2019; Published 2 May 2019

Guest Editor: Kunal Mondal

Copyright ( 2019 Bui Thi Hoan et al. This is an open access article distributed under the Creative Commons Attribution License, which permits unrestricted use, distribution, and reproduction in any medium, provided the original work is properly cited.

Highly luminescent carbon dots (C-dots) were synthesized by the one-pot simple hydrothermal method directly from lemon juice using different temperatures, time, aging of precursors, and diluted solvents to control the luminescence of C-dots. The obtained C-dots were characterized by high-resolution transmission electron microscopy, X-ray photoelectron spectroscopy, Fourier transform infrared spectrophotometry, dynamic light scattering, ultraviolet-visible spectrophotometry, and photoluminescent spectrophotometry. The results show that C-dots had strong green light emission with quantum yield in the range of 14.86 to $24.89 \%$ as a function of hydrothermal temperatures. Furthermore, light emission that is dependent on hydrothermal time, aging of precursor, and diluted solvent was observed. These results suggest that the $\mathrm{C}$-dots have potential application in optoelectronics and bioimaging.

\section{Introduction}

Carbon quantum dots (C-dots) have received considerable attention in bioimaging because of their highly biocompatibility, luminescent properties, and sphere-shaped nanoparticles $[1,2]$. Generally, the synthesis of C-dots involves the carbonization of carbon sources. Among different resources, natural sources become widely accepted as green precursors, which have great advantages in biomedicine because they are simple, repeatable, environment friendly, and cost-effective for the synthesis of C-dots $[3,4]$. Therefore, considerable effort has been made to synthesize C-dots from abundant natural resources. For example, C-dots derived from apple juice emit a wavelength of $428 \mathrm{~nm}$ with a quantum yield of $6.4 \%$ under the excitation of ultraviolet light of $340 \mathrm{~nm}$ [5]. Quantum yield of C-dots prepared from strawberries is 6.3\%. Maximum wavelength was $427 \mathrm{~nm}$ when they were excited by a wavelength of $340 \mathrm{~nm}$ [6]. C-dots derived from orange juices with a quantum yield of $26 \%$ were documented [7]. Recently, C-dots derived from Acacia concinna seeds exhibiting strong emission at $468 \mathrm{~nm}$ when excited at $390 \mathrm{~nm}$ with a quantum yield of $10.2 \%$ were also reported [8]. In addition to fruit juices, plant wastes such as pomelo peel [9], willow bark [10], and watermelon peel [11] can be used for synthesizing C-dots. Most natural C-dots emit short wavelengths when they are excited by short excitation wavelengths. However, short excitation wavelengths of high energy will cause the destruction of tissue and cells which limit its application in bioimaging and biomedicine. Recently, C-dots were synthesized successfully in our laboratory by the hydrothermal treatment of lemon juices [12]. In that research, we investigated the effect of hydrothermal temperature on the green luminescence of the C-dots under relatively long wavelength of excitation $(420 \mathrm{~nm})$. To expand this research, we herein report the effect of hydrothermal time, diluting solvents, type of precursor and excitation wavelength to the luminescence of C-dots. To the best of our knowledge, this is the first time the effect of hydrothermal time and type of precursor to the luminescence of C-dots prepared from lemon juices are studied, which would build up more scientific information about C-dots field for designing strong and stable light emission in bioimaging and nanomedicine. The microstructure of the $\mathrm{C}$-dots was 


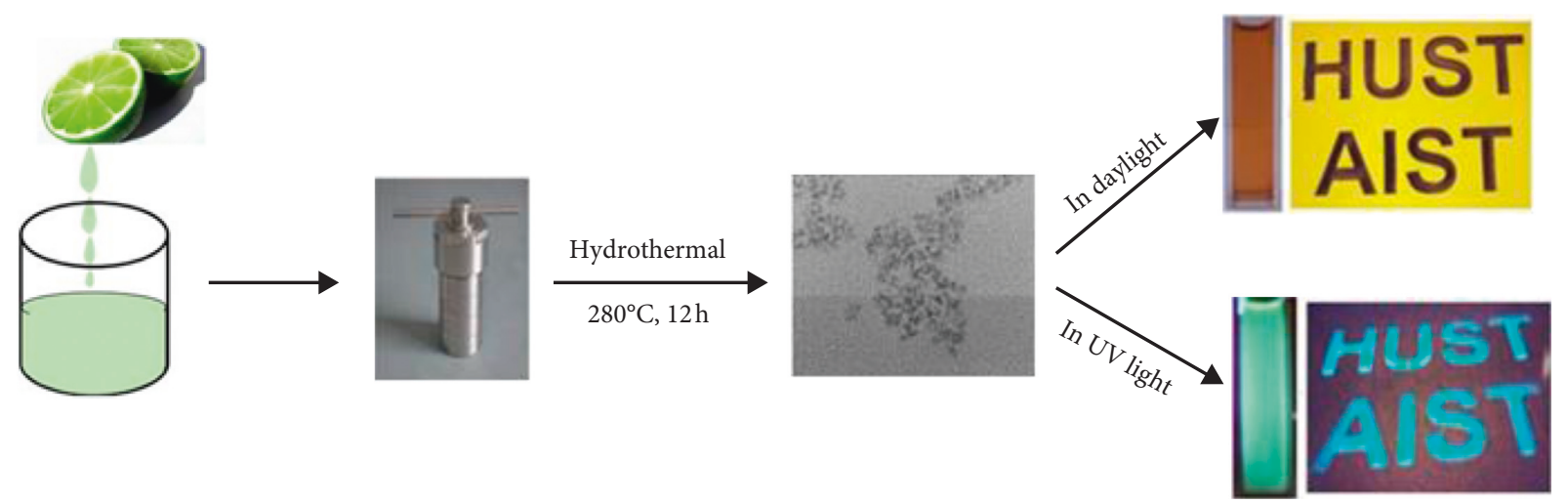

FIGURE 1: Schematic description of hydrothermal process of lemon juice for synthesis of C-dots and HUST and AIST characters building from C-dots under visible light and UV light.

characterized by high-resolution transmission electron microscopy (HRTEM). Chemical bonding of the C-dots was determined by Fourier transform infrared (FTIR) spectroscopy. Optical properties of C-dots were also determined using $\mathrm{UV}-\mathrm{Vis}$ and photoluminescence spectrometer, respectively.

\section{Experimental Procedure}

In a typical experiment, $40 \mathrm{~mL}$ of extract lemon juice (ivorywhite solution) was put into a Teflon-lined stainless steel autoclave for hydrothermal treatment at 120 to $280^{\circ} \mathrm{C}$ for $12 \mathrm{~h}$. After the reaction, the autoclave was naturally cooled to room temperature. During this hydrothermal process, ivorywhite solution changed to dark brown solution, indicating the formation of C-dots. These carbon dots were then purified to remove the larger nanoparticles by $2 \mu \mathrm{m}$ filter paper. The microstructure and particles size distribution of the C-dots were determined by using high-resolution transmission electron microscope, HRTEM (JEM 2100, JEOL Techniques, Tokyo, Japan), and dynamic light scattering (DLS, Malvern, England), respectively. Chemical bonding of the C-dots were measured with Fourier transform infrared spectroscopy (FTIR using a Perkin-Elmer Spectrum BX spectrometer) using $\mathrm{KBr}$ pellets and X-ray photoelectron spectrometer (XPS, Multilab 2000, Thermo Fisher Scientific, USA). Optical absorption and room temperature PL of the C-dots were performed using a Cary 500 spectrophotometer and a NANO LOG spectrofluorometer (Horiba, Edison, NJ, USA) equipped with a $450 \mathrm{~W}$ xenon arc lamp.

\section{Results and Discussion}

Figure 1 shows schematic of the conversion of lemon juices into C-dots. As shown in Figure 1, the ivory-white solution of lemon juices was changed to dark brown solution, indicating the formation of C-dots. This solution emitted green color under ultraviolet excitation. This result indicated the essential role of hydrothermal treatment for synthesis of C-dots. The formation of C-dots in the bottom-up method usually goes through three steps: (i) pyrolysis of carbonaceous precursors at high temperatures, resulting in (ii) carbonization and nucleation, followed by (iii) surface passivation by stable agents. Lemon contains very little fat and protein. Its composition consists mainly of carbohydrates (10\%) and water (88-89\%). Carbohydrates in lemon juices usually contain fiber and sugars such as sucrose, fructose, and glucose. The scientists suggest that any carbohydrate containing $\mathrm{C}, \mathrm{H}$, and $\mathrm{O}$ in a ratio of $1: 2: 1$ where $\mathrm{C}$ and $\mathrm{O}$ exist in the form that allows dehydration under hydrothermal conditions can be used to prepare C-dots [13]. The synthesis of C-dots from lemon juice involves the carbonization of its constituents. Under hydrothermal treatment, sucrose undergoes hydrolysis to produce glucose and fructose. Surface passivation is considered to be an important step in production of luminescent C-dots with high quantum yield. Here, we have obtained strong luminescence C-dots without any surface passivation.

Figures 2(a) and 2(b) show the HRTEM image of C-dots synthesized at 200 and $240^{\circ} \mathrm{C}$. As shown in Figures 2(a) and 2(b), the apparent black spots observed in the images indicate the formation of separate $\mathrm{C}$-dots. In addition, a calculated size distribution of C-dots synthesis at 200 and $240^{\circ} \mathrm{C}$ is in the range of $\sim(12-15) \mathrm{nm}$ and $\sim(3-5) \mathrm{nm}$, respectively.

HRTEM image does not show discernible lattice structures of C-dots on the higher magnification, suggesting that C-dots are amorphous dots. Although many scientists have demonstrated the existence of a $\mathrm{sp}^{2}$ crystal carbon, most of the C-dots have weak crystallinity $[13,14]$. Similar to natural source-derived C-dots, lemon juice-derived C-dots also have amorphous nature in this study.

The XPS spectrum of the C-dots given in Figure 2(c) showed a peak at around $284.71 \mathrm{eV}$ and another peak at $529.63 \mathrm{eV}$ attributable to the $\mathrm{C} 1 \mathrm{~s}$ and $\mathrm{O} 1 \mathrm{~s}$, respectively. The high-resolution spectrum of $\mathrm{C} 1 \mathrm{~s}$ showed that carbon is present in three chemical bonds of C-C at $284.91 \mathrm{eV}$ [1], $\mathrm{C}-\mathrm{OH}$ at $285.6 \mathrm{eV}$ [7], and $\mathrm{C}=\mathrm{O}$ at $289 \mathrm{eV}$ (Figure 2(d)).

The existence of chemical bonds is demonstrated by the infrared spectrum (Figure 3 ). The peak of $1713 \mathrm{~cm}^{-1}$ corresponds to the characteristic amplitude $\mathrm{C}=\mathrm{O}[7,15]$. The adsorption peaks at 1390 and $2925 \mathrm{~cm}^{-1}$ indicate the existence of the $\mathrm{C}-\mathrm{H}$ bond [15]. Peaks at $1360 \mathrm{~cm}^{-1}$ are thought to be related to the vibration of the $\mathrm{COOH}$ group. The existence of this peak is attributed to the presence of acids in C-dots when the temperature varies between 150 and $200^{\circ} \mathrm{C}$ 


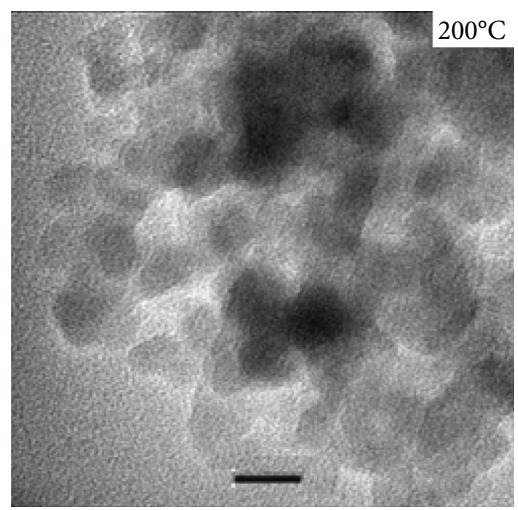

(a)

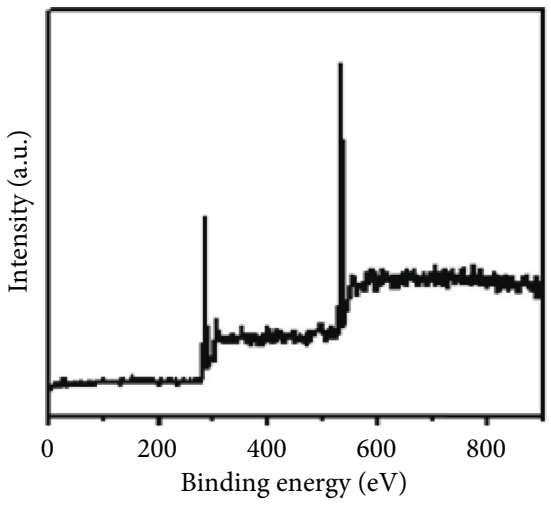

(c)

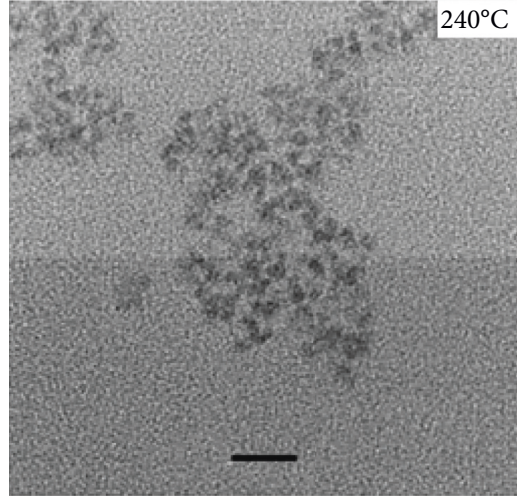

(b)

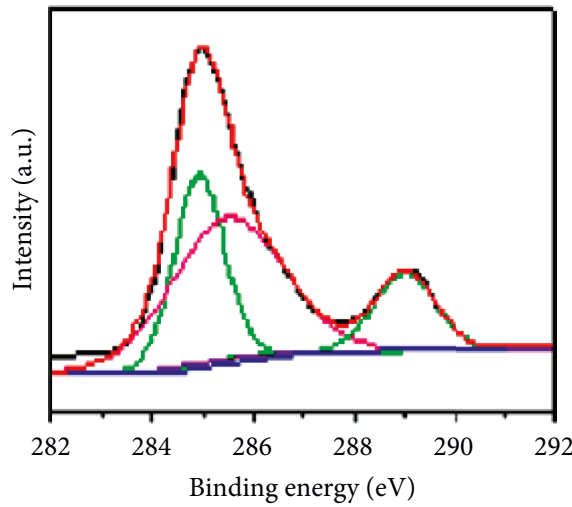

(d)

FIgURE 2: Characterizations of C-dots. (a, b) HRTEM image (the scale bar: $20 \mathrm{~nm}$ ), (c) XPS spectrum, and (d) high-resolution XPS spectra of C1s of C-dots.

[16]. The peak of $1124 \mathrm{~cm}^{-1}$ corresponds to the stretching mode of the C-O-C bond [17].

Figures 4(a) and 4(b) show DLS and zeta potential of $\mathrm{C}$-dots synthesized at $240^{\circ} \mathrm{C}$ at $12 \mathrm{~h}$. As shown in Figure $4(\mathrm{a})$, the synthesized C-dots are $\sim 50 \mathrm{~nm}$ in size, which could be due to the agglomeration of the C-dots. The obtained zeta potential result shows that the C-dots are $\sim 9.48 \mathrm{mV}$, which suggests relatively good dot stability (Figure $4(\mathrm{~b})$ ).

Figure 5 shows the UV-Vis spectra of C-dots synthesized at different temperatures. As shown in Figure 5, the C-dots synthesized at $150,200,240$, and $280^{\circ} \mathrm{C}$ displayed similar UV-Vis absorption center. Absorption peak at $283 \mathrm{~nm}$ corresponds to the transition $\pi-\pi$ of $\mathrm{C}=\mathrm{C}$ bond. The UV-Vis absorption spectrum has no background absorption in the visible area. This result demonstrated that there are no other forms of nanocarbon produced during the partial carbonization of precursors which are usually absorbed at longer wavelengths [18].

The photoluminescence excitation (PLE) spectrum of the $\mathrm{C}$-dots is measured by monitoring the emission at $510 \mathrm{~nm}$ as shown in Figure 6(a). The PLE spectrum of the C-dots synthesized at $240-280^{\circ} \mathrm{C}$ shows peak centered in the range of $410-440 \mathrm{~nm}$. However, the PLE spectrum of the C-dots synthesized at $150-200^{\circ} \mathrm{C}$ displays peak centered in the range of $450-480 \mathrm{~nm}$. Maximum excitation wavelengths for all C-dots range from 400 to $480 \mathrm{~nm}$. Figure 6(b) shows the luminescent spectra of C-dots obtained at different temperatures in $12 \mathrm{~h}$. Emission peak is displayed in the green

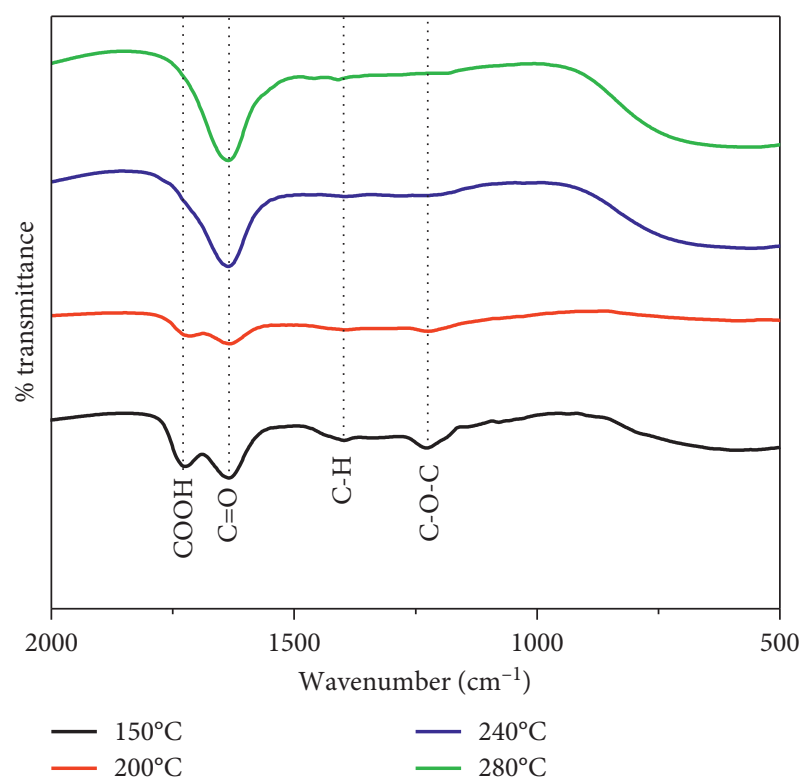

FIGURE 3: FTIR spectrum of C-dots.

region between 500 and $550 \mathrm{~nm}$ depending on the hydrothermal temperature. In particular, C-dots synthesized at $150,200,240$, and $280^{\circ} \mathrm{C}$ have corresponding emissive peaks at 550,540, 518, and $508 \mathrm{~nm}$. When the hydrothermal temperature decreased, the radiation wavelength was red- 


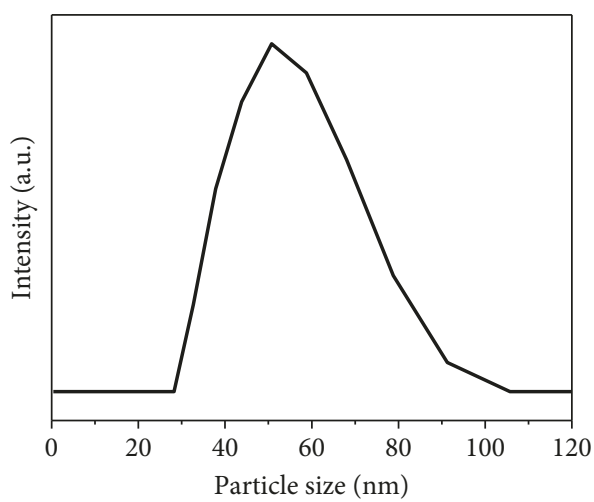

(a)

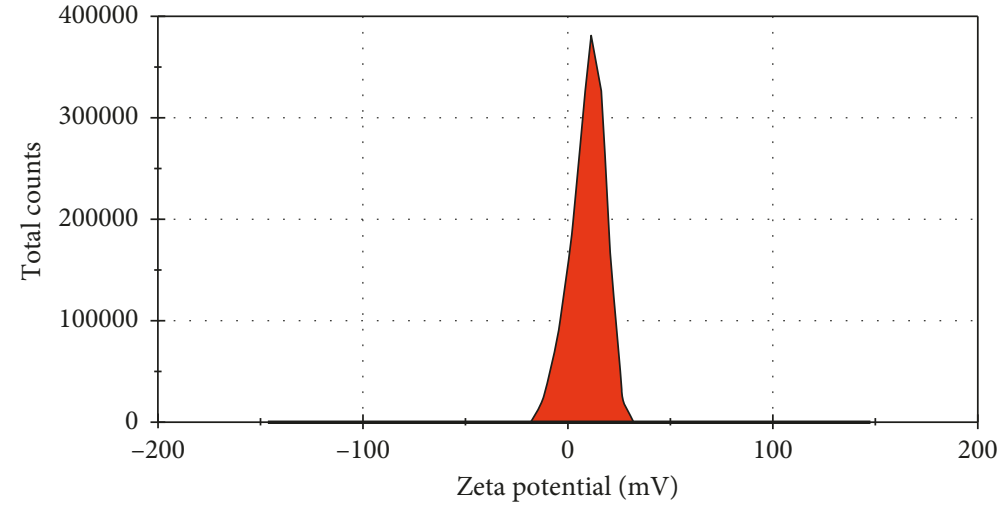

(b)

Figure 4: (a) DLS graph and (b) zeta potential graph of C-dots synthesized at $240^{\circ} \mathrm{C}$.

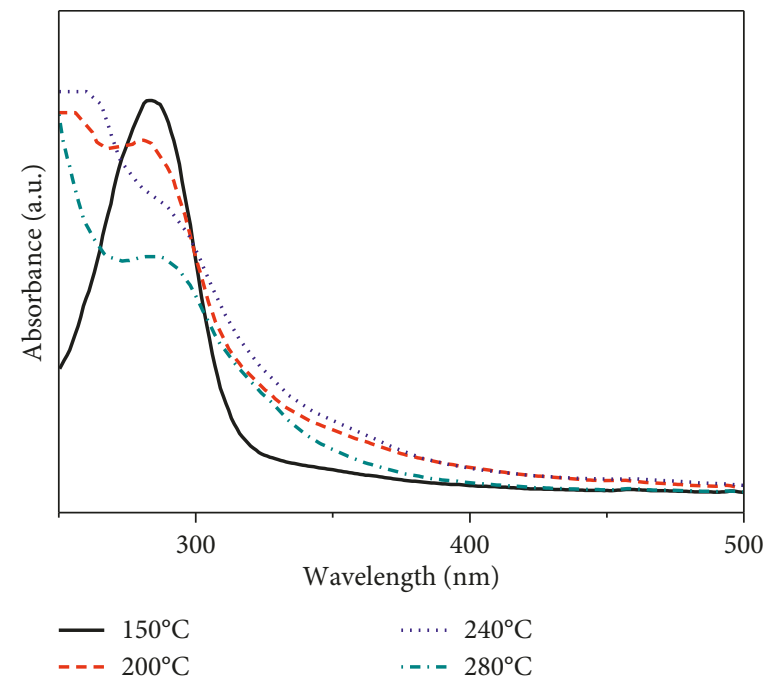

Figure 5: UV-Vis spectra of C-dots synthesized from lemon juice at $150,200,240$, and $280^{\circ} \mathrm{C}$.

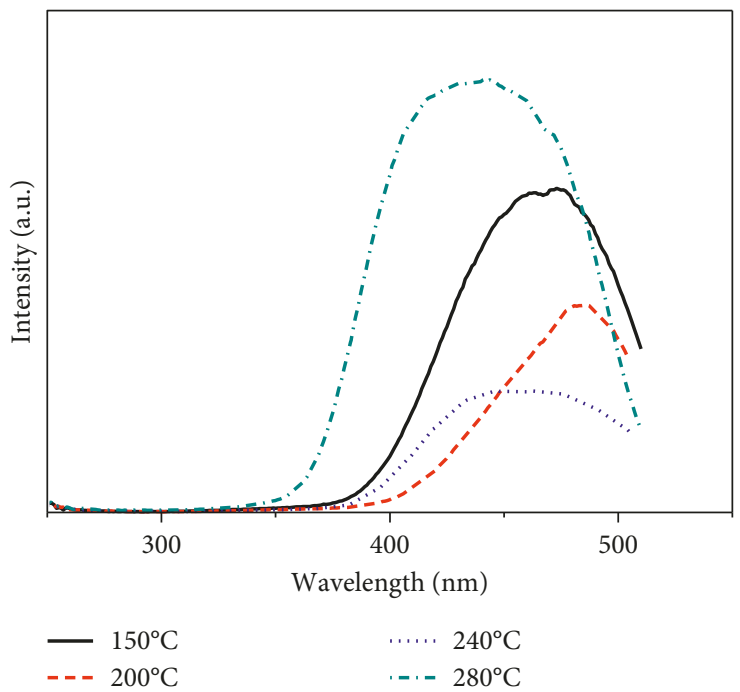

(a)

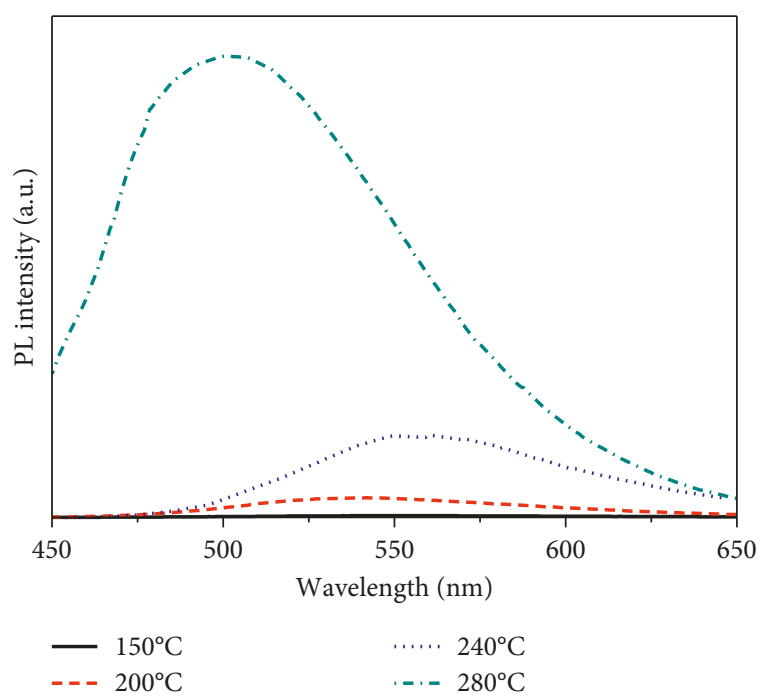

(b)

FIgure 6: Optical properties of C-dots. (a) PLE spectra and (b) PL spectra of C-dots synthesized at different temperatures. 


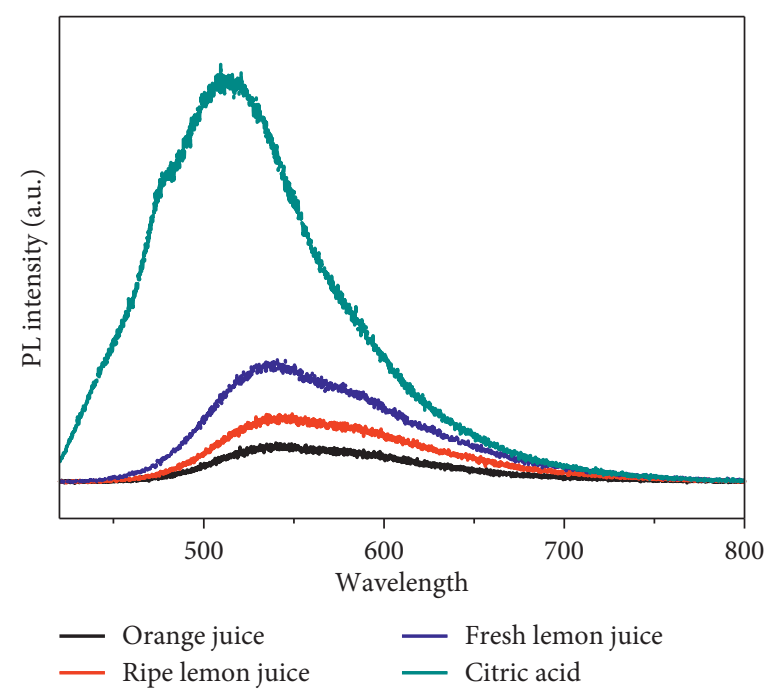

FIGURE 7: Luminescence of C-dots synthesized from citric acid and different natural sources.

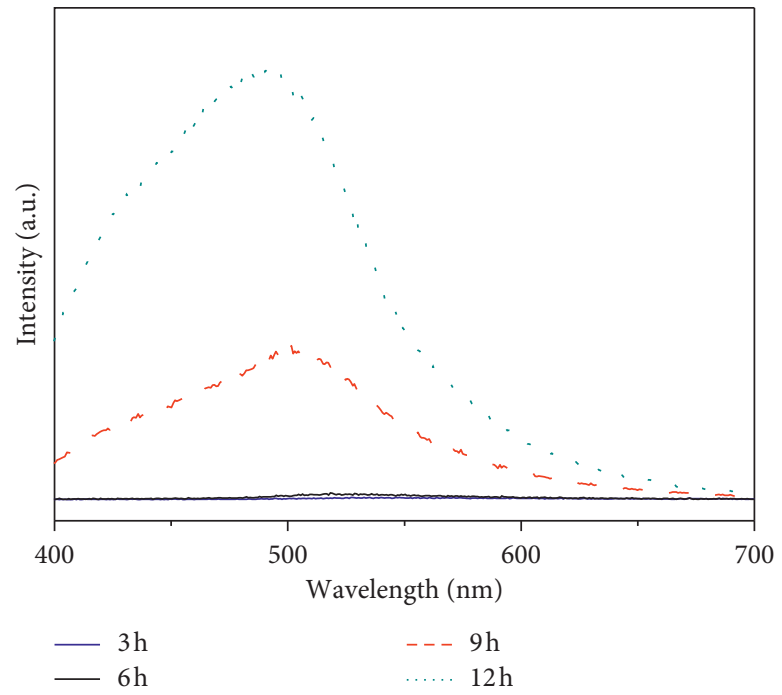

(a)

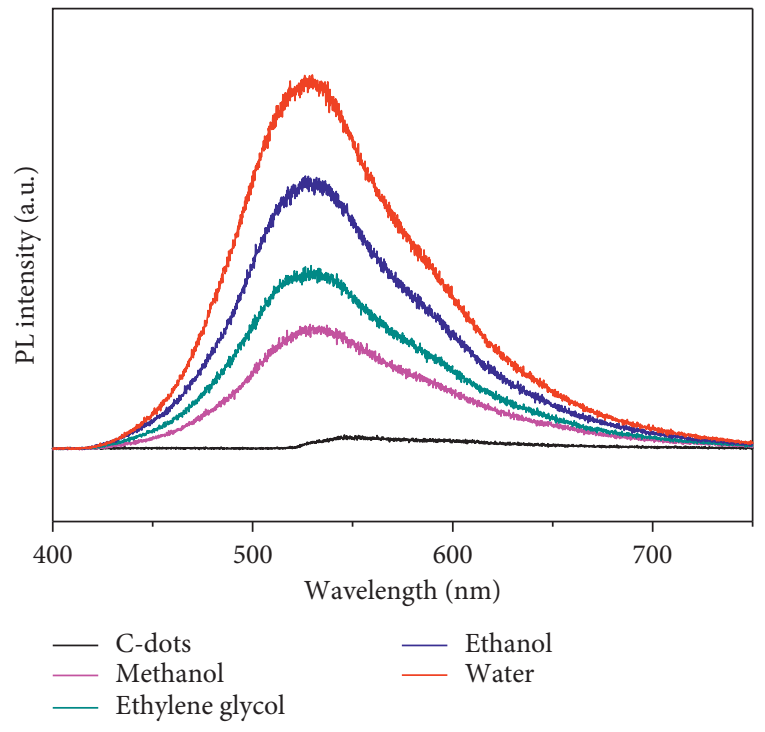

(b)

Figure 8: Luminescence spectra of C-dots synthesized at (a) $280^{\circ} \mathrm{C}$ with different hydrothermal time and (b) $200^{\circ} \mathrm{C}$ in $12 \mathrm{~h}$ in various diluted solvents.

shifted. These results could be attributed to effect of the particles size of the C-dots as increasing temperature. In other words, C-dots with the larger particle size will be preferred to emit longer wavelengths due to the quantum confinement effect [19].

To understand the role of citric acid in comparison with different precursors used in the hydrothermal synthesis of C-dots, we tested ripe lemon juice, fresh lemon juice, and orange juice. The PL spectra of C-dots with variation of precursors are shown in Figure 7. A strong PL emission peak located at $500 \mathrm{~nm}$ is observed for the citric acid precursor. The emission peak is shifted to a higher wavelength when lemon juice and orange juice are used as precursors. The citric acid shows the highest PL intensity. It is also seen that a higher PL is observed for lemon juices compared to that of orange juices. This result is because lemon juices have higher concentration of citric acid do orange juices. From the PL spectra of the C-dots, it is clear that higher PL is observed for fresh lemon juices compared to ripe lemon juices. This result explains that the ripe lemon juices led to significant decrease in the grade of constituents and destroyed their surface structure, decreasing the PL emission.

Luminescent spectra of the C-dots at $280^{\circ} \mathrm{C}$ in different hydrothermal times of $3,6,9$, and $12 \mathrm{~h}$ are shown in Figure 8(a). It is found that the hydrothermal time does not affect the maximum peak position, but influences the fluorescence intensity. As the hydrothermal time increases, the intensity of the emission increases. Hydrothermal treatments can generate a combination of temperatures and pressure effect in the lemon juice precursors, causing the 


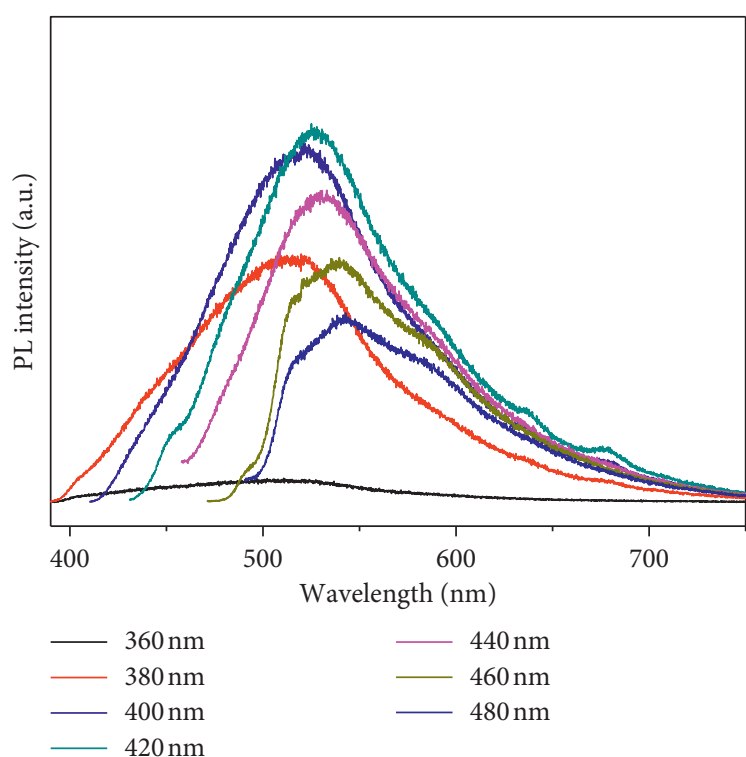

(a)

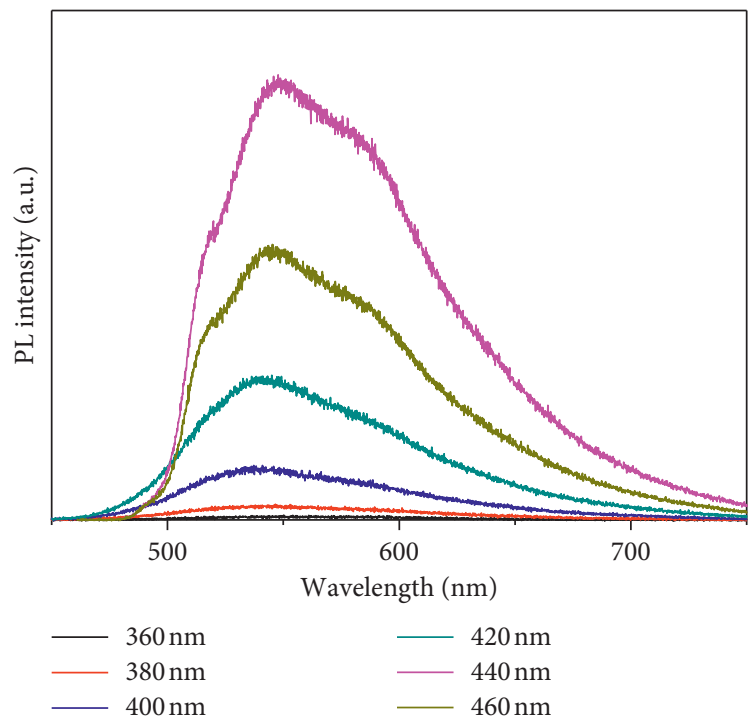

(c)

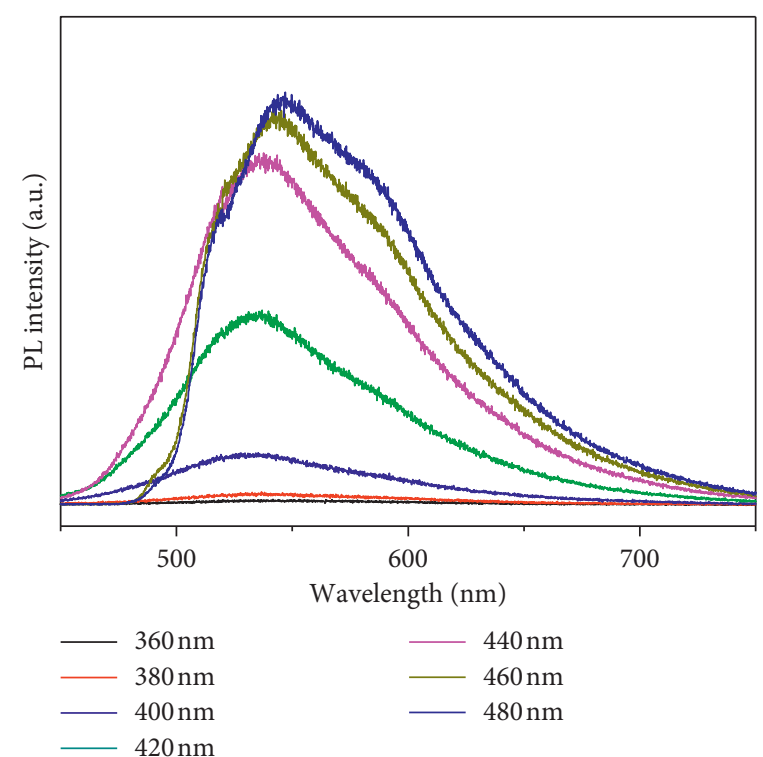

(b)

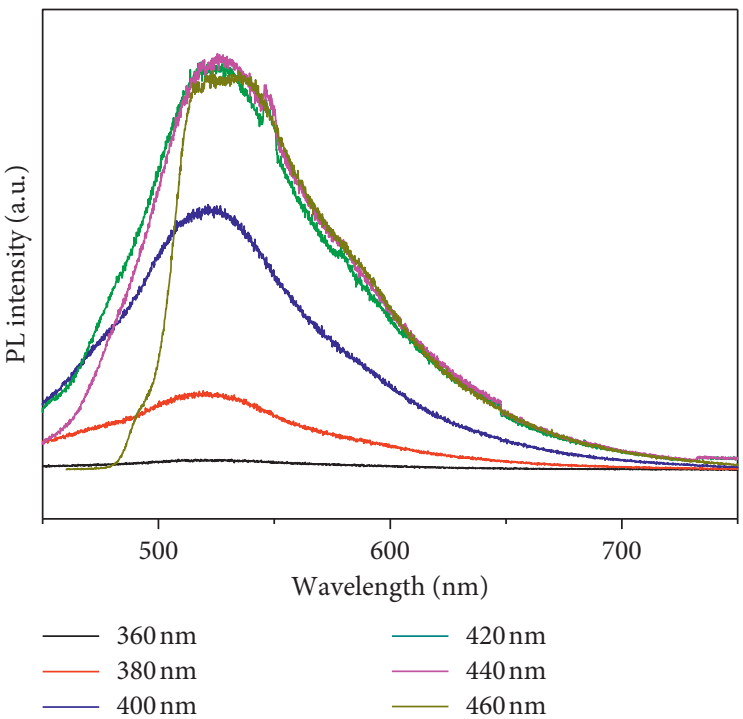

(d)

Figure 9: PL spectra of C-dots synthesized at different temperatures monitored by various excitation wavelengths: (a) $120^{\circ} \mathrm{C}$, (b) $150^{\circ} \mathrm{C}$, (c) $200^{\circ} \mathrm{C}$, and $(\mathrm{d}) 240^{\circ} \mathrm{C}$.

constituents' dehydration, polymerization, and carbonization. In the hydrothermal process, the longer hydrothermal time could lead to more conversion of constituents into carbonization. Figure 8(b) shows the emission spectra of $\mathrm{C}$-dots in different solvents. The emission intensity of the C-dots in the polar solvent is significantly increased relative to the pure C-dots. It is observed that the luminescent intensity of C-dots in water is greatest. Since water has a higher polarization than organic solvents, C-dots in water exhibited the highest luminescent intensity. Similar results were observed in C-dots made from onion [17].

Figure 9 shows the luminescent spectra of C-dots at different temperatures with changing of excitation wavelengths. As the wavelength changed, the PL spectra of C-dots at different temperatures of $120,150,200$, and $240^{\circ} \mathrm{C}$ exhibited different wavelength dependencies. At low temperatures of $120^{\circ} \mathrm{C}$, there is a clear dependence of the maximum emission wavelength on excitation wavelength. When the temperature increased to $150^{\circ} \mathrm{C}$, it was observed that the degree of dependence of emission wavelength on excitation wavelength becomes less significance. When the hydrothermal temperature reached $200^{\circ} \mathrm{C}$, the luminescent peak was almost unrelated to the excitation wavelength. There are two main reasons for the dependence of luminescent spectra of C-dots synthesized at 120 and $150^{\circ} \mathrm{C}$ on excitation wavelength. The first reason is that at low temperatures, the particles are not uniform in size. Some scientists have demonstrated that $\mathrm{C}$-dots with different sizes have various bandgaps [20]. When light with a certain wavelength is projected into C-dots, particles of the same 


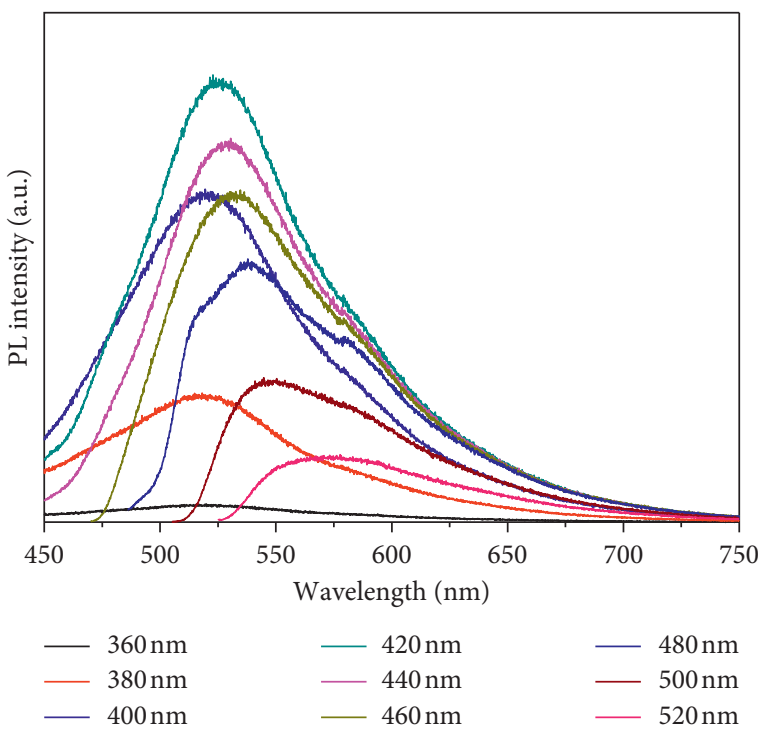

(a)

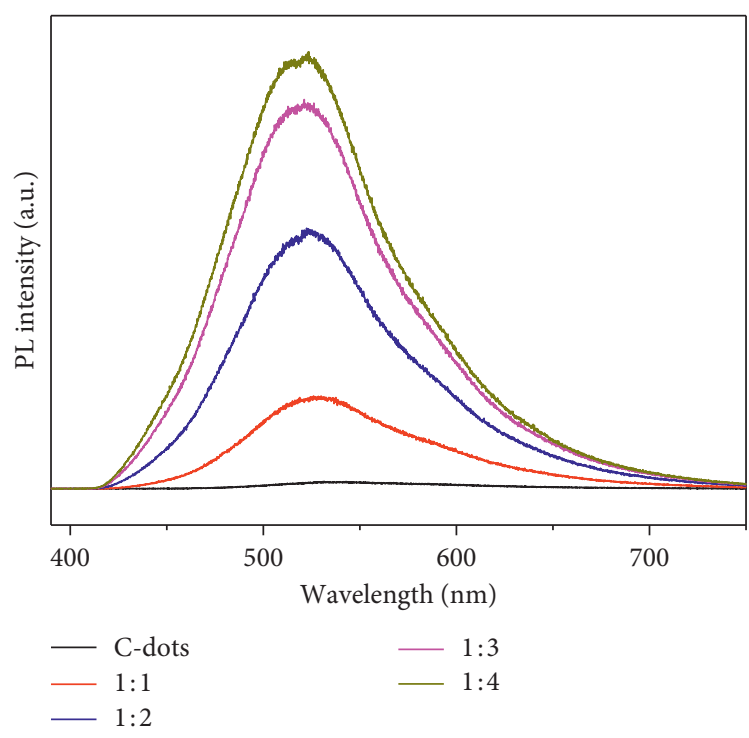

(b)

Figure 10: PL spectra of the diluted C-dots in deionized water (C-dots/DW). (a) Effect of excitation wavelength in C-dots/DW ratio of $1: 1$ specimen and (b) effect of C-dots/DW ratio.

size will give priority to the emission. When other wavelengths are projected, other sized particles will emit radiation. As a result, the emission spectrum of $\mathrm{C}$-dots depends on the excitation wavelength. When the hydrothermal temperature is high $\left(200^{\circ} \mathrm{C}\right.$ or higher), the size of C-dots particles becomes more uniform. Therefore, the dependence of the wavelength on the excitation wavelength is not observed. The latter causes the excitation-dependent behaviors of the emission spectra of the C-dots synthesized at low temperatures that are surface states. As we know, surface functional groups such as $\mathrm{C}=\mathrm{O}, \mathrm{COOH}$, and $\mathrm{C}-\mathrm{O}$ can generate their own energy levels. So there will be many ways of electron transfer from the excited state to the fundamental state of the photon emission. Observations on the FTIR spectra of C-dots produced at different temperatures (Figure 3) show that at low temperatures, the surface of the $\mathrm{C}$-dots contains $\mathrm{COOH}, \mathrm{C}-\mathrm{H}, \mathrm{C}-\mathrm{O}-\mathrm{C}$, and $\mathrm{C}=\mathrm{O}$ groups. At high temperatures, the $\mathrm{COOH}, \mathrm{C}-\mathrm{H}$, and $\mathrm{C}-\mathrm{O}-\mathrm{C}$ groups are removed and the $\mathrm{C}=\mathrm{O}$ group is dominated. This is the reson for excitation-independent luminescence of $\mathrm{C}$-dots prepared at high hydrothermal temperatures.

Figure 10(a) shows the luminescent spectrum of C-dots diluted with water at a volume ratio $1: 1$ monitored by different wavelengths. Unlike pure C-dots, diluted C-dots showed excitation wavelengths dependence luminescent properties. The emission peak shifted to a longer wavelength region when the excitation wavelength increased. The maximum emission intensity was observed at $524 \mathrm{~nm}$ when the excitation wavelength was $420 \mathrm{~nm}$. Similar results were observed in C-dots diluted with alcohol, ethylene glycol, and methanol. Due to the interaction of C-dots with polar solvents, a series of emission traps are generated. When C-dots are irradiated by light of a certain wavelength, these surface traps prevail. But when they are exposed to different wavelengths, other types of emission traps dominate. As a result, when C-dots are stimulated by different wavelengths, the emission wavelengths of the diluted C-dots depend on the excitation wavelength. Furthermore, the maximum emission intensity is sensitive to the amount of water added or otherwise sensitive to the concentration of C-dots (Figure 9(b)). In diluted C-dots, the probability of a collision is lower than that of the pure $\mathrm{C}$-dots because of the distance between the C-dots increase. Diluting C-dots in deionized water reduces collision extinguishment and selfabsorption in high concentrations. As a result, the luminescent intensity of diluted C-dots in the solvents was significantly increased.

Quantum yield (QY) is an important parameter for characterization of luminescent nanomaterials. The easiest method to determine QY involves comparing luminescent intensity of the sample with the standard compound. The selected standard and sample must be absorbed and emitted in the same regions. Because absorption spectra of sodium fluorescein and C-dots are located in the same region, sodium fluorescein is chosen as the standard for determining the QY of the C-dots. As known, the QY of sodium fluorescein was 0.79 when excited by $370 \mathrm{~nm}$ wavelength. Five different concentrations of the standard and the samples are mixed so that their absorption at $370 \mathrm{~nm}$ is less than 0.1. Sodium fluorescein is diluted in $0.1 \mathrm{M} \mathrm{NaOH}$, and C-dots are diluted with deionized water. The refractive index of $0.1 \mathrm{M} \mathrm{NaOH}$ solution and deionized water are 1.33. Absorption spectra of all samples are measured and their absorbance at $370 \mathrm{~nm}$ is determined. In addition, their luminescent spectra with an excitation wavelength of $370 \mathrm{~nm}$ were also measured. Figure 11 shows the dependence of integral luminescence intensity on the absorbance of both standard and C-dots produced at $150^{\circ} \mathrm{C}$ for $12 \mathrm{~h}$. Data show the linear dependence of integral luminescent intensity according to absorption. 


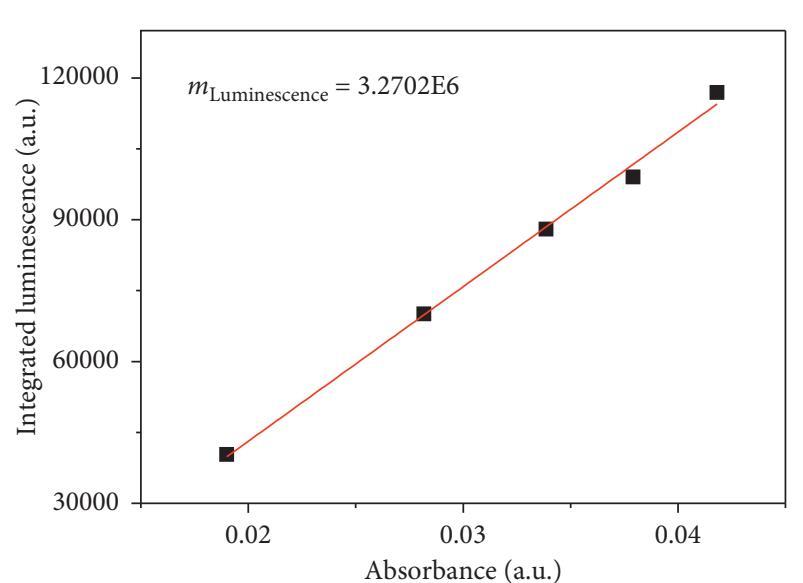

(a)

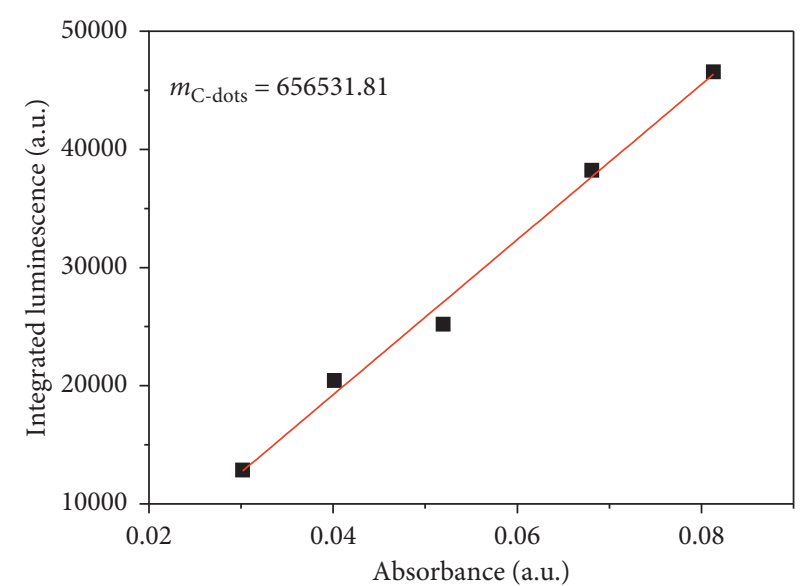

(b)

Figure 11: The dependence of luminescent intensity on the absorption of (a) sodium fluorescein and (b) C-dots synthesized at $150^{\circ} \mathrm{C}$ for $12 \mathrm{~h}$.

TABle 1: Comparison of the QYs of C-dots prepared by various natural precursors.

\begin{tabular}{lcccc}
\hline Precursor & Size $(\mathrm{nm})$ & Color & QYs (\%) & Ref. \\
\hline Apple juice & $2.8 \pm 0.4$ & Blue & 6.4 & {$[5]$} \\
Strawberry juice & 5.2 & Blue & 6.3 & {$[6]$} \\
Pomelo peel & $2 \pm 0.5$ & Blue & 6.9 & {$[9]$} \\
Willow bark & $1-4$ & Blue & 6.9 & {$[10]$} \\
Watermelon & $2 \pm 0.5$ & Blue & 7.1 & {$[11]$} \\
Orange juice & $1.5-4.5$ & Green & 26 & {$[7]$} \\
Fungus & $2.3 \pm 0.3$ & Blue & 15.3 & {$[21]$} \\
Carrot juice & $2-8$ & Blue & 5.16 & {$[22]$} \\
Soy milk & $13-40$ & Blue & & {$[23]$} \\
Garlic & $1-3$ & Blue & $5.1-10.5$ & {$[24]$} \\
Onion waste & 15 & Blue & 28 & {$[17]$} \\
Lemon juice & $3-5$ & Green & 21.37 & In this study \\
\hline
\end{tabular}

The quantum yields of C-dots are given by the following equation:

$$
\mathrm{QY}_{x}=\mathrm{QY}_{\mathrm{st}} \frac{m_{x}}{m_{\mathrm{st}}} \cdot \frac{n_{x}^{2}}{n_{\mathrm{st}}^{2}},
$$

where the subscripts st and $x$ represent the standard and sample, respectively, $m$ is the gradient from the plot of integrated luminescence intensity versus absorbance, and $n$ is the refractive index. The quantum yield of C-dots synthesized at $150^{\circ} \mathrm{C}$ is $14.86 \%$. The QY of C-dots synthesized at 200,240 , and $280^{\circ} \mathrm{C}$ for 12 hours when excited by $370 \mathrm{~nm}$ wavelengths using similar calculations is $16.87 \%, 21.37 \%$, and $24.89 \%$, respectively. These results could be attributed to effective conversion of natural acidic constituents into carbonization as increasing hydrothermal temperature of process which is approved by FT-IR results.

To understand the uses of C-dots synthesized from lemon juice, we compared the luminescence of lemon juicederived C-dots with other natural precursors, and their quantum yields are listed in Table 1 . These results clearly reveal that the lemon juice used in this study enhanced the quantum yields (QYs) to a certain extent.

\section{Conclusions}

In this article, we herein have demonstrated that the strong and stable green light emission of C-dots could be synthesized successfully by the one-pot of hydrothermal method. In particular, The PL intensity of the C-dots increases with increasing hydrothermal temperature and time. In addition, C-dots diluted by polar solvents induced stronger luminescence than did the pure $\mathrm{C}$-dots. The obtained C-dots having strong, inert, and stable luminescent properties would be particularly important for potential applications in optoelectronics and bioimaging.

\section{Data Availability}

The data used to support the findings of this study are included within the article.

\section{Conflicts of Interest}

The authors declare that they have no conflicts of interest.

\section{Acknowledgments}

This research was funded by the Ministry of Education and Training (MOET) under grant number B2017-BKA-51.

\section{References}

[1] S. Y. Lim, W. Shen, and Z. Gao, "Carbon quantum dots and their applications," Chemical Society Reviews, vol. 44, no. 1, pp. 362-381, 2015.

[2] G. Hong, S. Diao, A. L. Antaris, and H. Dai, "Carbon nanomaterials for biological imaging and nanomedicinal therapy," Chemical Reviews, vol. 115, no. 19, pp. 10816-10906, 2015.

[3] T. Pal, S. Mohiyuddin, and G. Packirisamy, "Facile and green synthesis of multicolor fluorescence carbon dots from curcumin: in vitro and in vivo bioimaging and other applications," ACS Omega, vol. 3, no. 1, pp. 831-843, 2018.

[4] H. Xu, X. Yang, G. Li, C. Zhao, and X. Liao, "Green synthesis of fluorescent carbon dots for selective detection of tartrazine 
in food samples," Journal of Agricultural and Food Chemistry, vol. 63, no. 30, pp. 6707-6714, 2015.

[5] Y. Xu, C. J. Tang, H. Huang et al., "Green synthesis of fluorescent carbon quantum dots for detection of $\mathrm{Hg}^{2+}$," Chinese Journal of Analytical Chemistry, vol. 42, no. 9, pp. 1252-1258, 2014.

[6] H. Huang, J. J. Lv, D. L. Zhou et al., "One-pot green synthesis of nitrogen-doped carbon nanoparticles as fluorescent probes for mercury ions," RSC Advances, vol. 3, no. 44, pp. 21691-21696, 2013.

[7] S. Sahu, B. Behera, T. K. Maiti, and S. Mohapatra, "Simple one-step synthesis of highly luminescent carbon dots from orange juice: application as excellent bio-imaging agents," Chemical Communications, vol. 48, no. 70, pp. 8835-8837, 2012.

[8] J. R. Bhamore, S. Jha, T. J. Park, and S. K. Kailasa, "Fluorescence sensing of $\mathrm{Cu}^{2+}$ ion and imaging of fungal cell by ultra-small fluorescent carbon dots derived from Acacia concinna seeds," Sensors and Actuators B: Chemical, vol. 277, pp. 47-54, 2018.

[9] W. Lu, X. Qin, S. Liu et al., "Economical, green synthesis of fluorescent carbon nanoparticles and their use as probes for sensitive and selective detection of mercury(II) ions," Analytical Chemistry, vol. 84, no. 12, pp. 5351-5357, 2012.

[10] X. Qin, W. Lu, A. M. Asiri, A. O. Al-Youbi, and X. Sun, "Green, low-cost synthesis of photoluminescent carbon dots by hydrothermal treatment of willow bark and their application as an effective photocatalyst for fabricating $\mathrm{Au}$ nanoparticles-reduced graphene oxide nanocomposites for glucose detection," Catalysis Science \& Technology, vol. 3, no. 4, pp. 1027-1035, 2013.

[11] J. Zhou, Z. Sheng, H. Han, M. Zou, and C. Li, "Facile synthesis of fluorescent carbon dots using watermelon peel as a carbon source," Materials Letters, vol. 66, no. 1, pp. 222-224, 2012.

[12] B. T. Hoan, P. Van Huan, H. N. Van et al., "Luminescence of lemon-derived carbon quantum dot and its potential application in luminescent probe for detection of $\mathrm{Mo}^{6+}$ ions," Luminescence, vol. 33, no. 3, pp. 545-551, 2018.

[13] A. B. Siddique, A. K. Pramanick, S. Chatterjee, and M. Ray, "Amorphous carbon dots and their remarkable ability to detect 2,4,6-trinitrophenol," Scientific Reports, vol. 8, no. 1, 9770 pages, 2018

[14] M. Hasan, V. G. Gomes, A. Dehgani, and S. M. Ardekani, "Engineering carbon quantum dots for photomediated theranostics," Nano Research, vol. 11, pp. 1-41, 2018.

[15] P. C. Hsu, Z. Y. Shih, C. H. Lee, and H. T. Chang, "Synthesis and analytical applications of photoluminescent carbon nanodots," Green Chemistry, vol. 14, no. 4, pp. 917-920, 2012.

[16] J. Deng, Q. Lu, N. Mi et al., "Electrochemical synthesis of carbon nanodots directly from alcohols," Chemistry-A European Journal, vol. 20, no. 17, pp. 4993-4999, 2014.

[17] R. Bandi, B. R. Gangapuram, R. Dadigala, R. Eslavath, S. S. Singh, and V. Guttena, "Facile and green synthesis of fluorescent carbon dots from onion waste and their potential applications as sensor and multicolour imaging agents," RSC Advances, vol. 6, no. 34, pp. 28633-28639, 2016.

[18] K. M. Tripathi, T. S. Tran, T. T. Tung, D. Losic, and T. Kim, "Water soluble fluorescent carbon nanodots from biosource for cells imaging," Journal of Nanomaterials, vol. 2017, Article ID 7029731, 10 pages, 2017.

[19] S. Lin, Y. Cheng, C. Lin, J. Fang, W. Xiang, and X. Liang, "Carbon nanodots with intense emission from green to red and their multifunctional applications," Journal of Alloys and Compounds, vol. 742, pp. 212-219, 2018.
[20] W. Kwon, G. Lee, S. Do, T. Joo, and S. W. Rhee, "Sizecontrolled soft-template synthesis of carbon nanodots toward versatile photoactive materials," Small, vol. 10, no. 3, pp. 506-513, 2014.

[21] K. Yang, M. Liu, Y. Wang et al., "Carbon dots derived from fungus for sensing hyaluronic acid and hyaluronidase," Sensors and Actuators B: Chemical, vol. 251, pp. 503-508, 2017.

[22] Y. Liu, Y. Liu, M. Park et al., "Green synthesis of fluorescent carbon dots from carrot juice for in vitro cellular imagingfluorescent carbon dots from carrot juice for in vitro cellular imaging," Carbon Letters, vol. 21, pp. 61-67, 2017.

[23] C. Zhu, J. Zhai, and S. Dong, "Bifunctional fluorescent carbon nanodots: green synthesis via soy milk and application as metal-free electrocatalysts for oxygen reduction," Chemical Communications, vol. 48, no. 75, pp. 9367-9369, 2012.

[24] C. Sun, Y. Zhang, P. Wang et al., "Synthesis of nitrogen and sulfur Co-doped carbon dots from garlic for selective detection of $\mathrm{Fe}^{3+}$," Nanoscale Research Letters, vol. 11, no. 1, p. 110, 2016. 


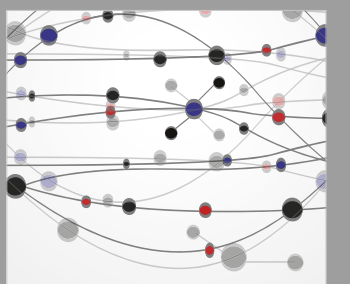

The Scientific World Journal
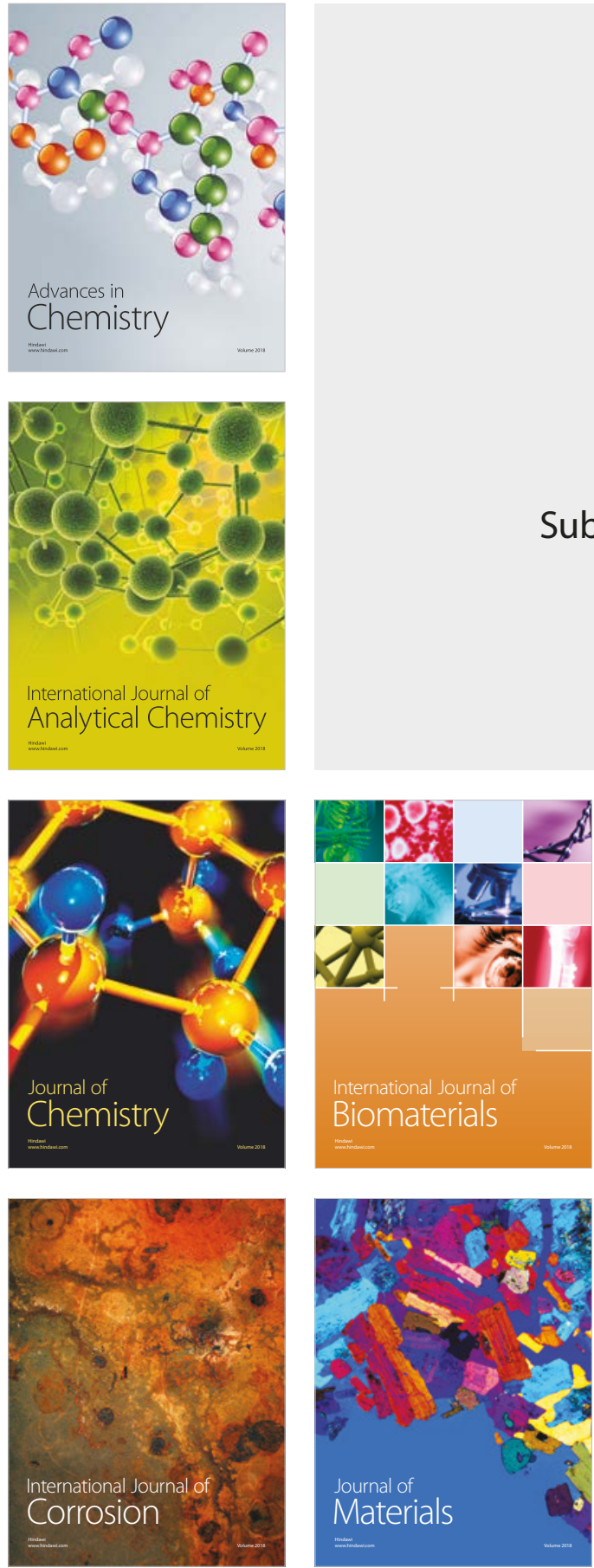

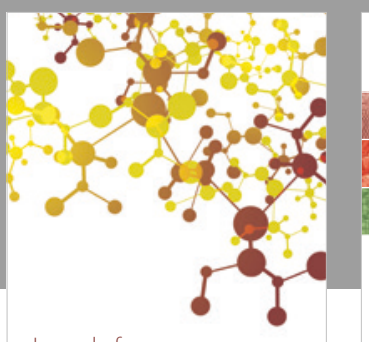

Journal of

Applied Chemistry
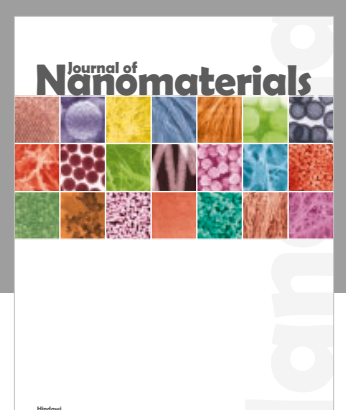

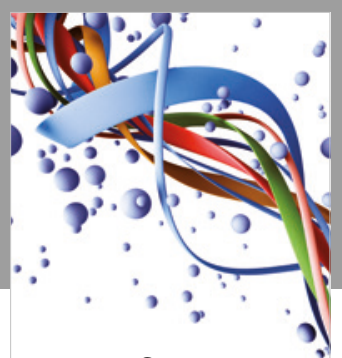

Scientifica

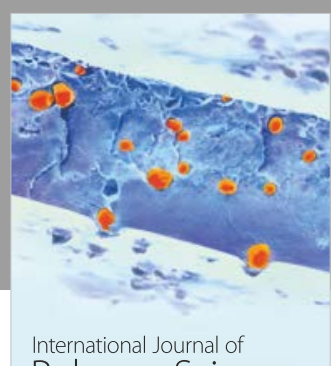

Polymer Science

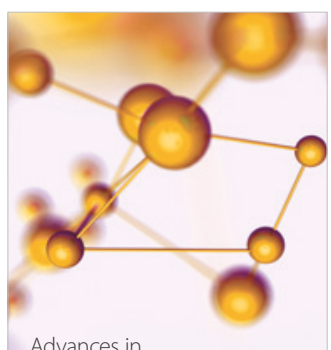

Physical Chemistry
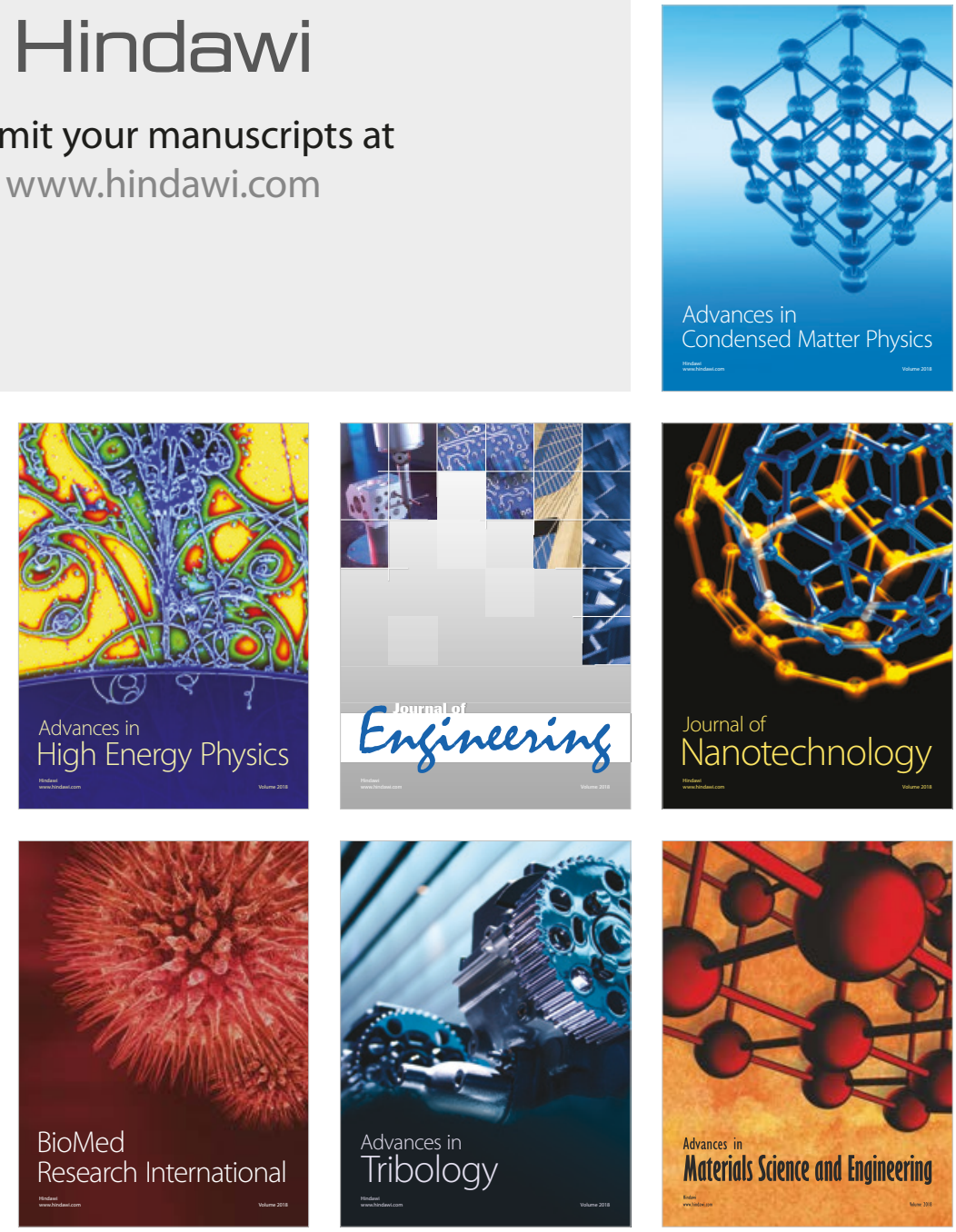